\title{
The Paradox of Increasing both Enrollment and Graduation Rates: Acknowledging Elephants in the Ivory Tower
}

\author{
Sean W. Mulvenon ${ }^{1} \&$ Daniel H. Robinson ${ }^{2}$ \\ ${ }^{1}$ University of Arkansas, USA \\ ${ }^{2}$ School of Education, Colorado State University, Fort Collins, Colorado 80523-1588, USA \\ Correspondence: Daniel H. Robinson, School of Education, 1588 Campus Delivery, Colorado State University, Fort \\ Collins, Colorado 80523-1588, USA. E-mail: dan.robinson@colostate.edu
}

Received: October 30, 2013

Accepted: November 25, 2013

Online Published: December 1, 2013

doi:10.5430/ijhe.v3n1p66

URL: http://dx.doi.org/10.5430/ijhe.v3n1p66

\begin{abstract}
The argument is made that increasing enrollments and graduation rates cannot occur while maintaining academic standards. Several U.S. universities are attempting to increase their enrollments to counter the financial difficulties created by a reduction in state support. These same universities are also under growing pressure from their state legislatures to increase four-year graduation rates and make degrees more affordable. In this essay, we describe how some universities and programs are attempting to meet both of these goals by lowering academic standards.
\end{abstract}

Keywords: Graduation rates, Diploma mills, Enrollment, Academic standards, Education majors

On September 8, 2012, the Savannah State University football team lost to Florida State University 55-0. The week prior, they lost to Oklahoma State University by a score of 84-0. On Sept 21, 2013 they lost to the University of Miami 77-7. Why is the Savannah State football team playing such high-powered teams? Money! The payouts to Savannah State and other institutions willing to play major conference football teams are very lucrative. In fact, ESPN reported Savannah State would receive $\$ 675,000$ for these two games, and that the athletic director at Savannah State expected to "book" at least two such games every year. An ESPN reporter questioned the integrity of these types of "money" games. Our immediate reaction was this type of "moneyball" game is not limited to higher education sports; it is also occurring in higher education academic degree programs!

In recent years, there has been increasing pressure in higher education to increase both enrollments and graduation rates (Bankston, 2011). This call is typically championed with a chorus of platitudes regarding the numerous benefits (i.e., increased opportunities for students - particularly traditionally disadvantaged students, economic benefits for the state, outreach, etc.). All of this makes for great political rhetoric for university administrators, but it raises three important questions: (1) Has admitting more students and graduating them faster impacted the academic expectations and rigor associated with the attainment of a college degree?(2) What are the negative consequences associated with such goals? (3) Can higher education effectively increase enrollments and graduation rates and maintain the traditional academic rigor and expectations for attaining college degrees? In short, can the diplomas awarded avoid the stigma of the old adage "not worth the paper it's printed on"?

As professors in colleges of education, we have both experienced the demands within our universities to grow enrollment and increase the number of undergraduate and graduate degrees granted from our institutions. Growing opportunities for students to attain college degrees is a laudable goal, and one we believe has always been pursued at our institutions. What we question here are both the methods used to attain the goals of increased enrollment and awarding of undergraduate and graduate degrees. As college of education professors in graduate degree programs, we have both been challenged to reduce academic expectations and rigor by other degree programs, our administration, and through peer pressure from other graduate faculty members. What follows represents our perspectives as education professors regarding the impact of the attenuation of academic rigor in the pursuit of higher enrollments and awarding of undergraduate and graduate degrees in education.

\section{Higher Education Funding}

In recent years, the percentage of funding for public institutions of higher education contributed by state legislatures has declined, requiring universities and colleges to identify alternative sources of revenue (Wellman, 2008; Congressional Documents, 2012; Max \& Tierney, 2011). Colleges of education represent an interesting academic 
anomaly in the quest for additional funding, specifically by increasing enrollment in and granting degrees of higher education. We have comparatively low infrastructure costs (e.g., no lab expenses compared to the sciences), a demonstrated willingness to create online or distance education versions of our courses, and a consistent/reliable source of students for graduate degree programs. For example, the primary method for K-12 teachers to increase their annual pay is through step-raises, where raise amounts are linked to completion of graduate credit hours and graduate degrees. The assumption is the attainment of advanced degrees by teachers and administrators will result in higher achievement by students in the K-12 system. The Ohio Education Association provides a table of "Annual Step Increases - Statewide" and outlines the automatic raises for teachers with a master's degree (Ohio Education Association, 2013).

The 2010 Digest of Education Statistics reports that 52\% of teachers have a masters, specialist, or doctoral degree. A commensurate statistic for K-12 administrators is not compiled, but most K-12 administrator certification programs require an advanced degree, so it can be assumed the number of administrators with graduate degrees approaches $100 \%$. As teachers and administrators complete graduate courses and degrees they increase their salaries and subsequently the cost of a K-12 education for the average student. According to the 2009 U.S. Census Bureau, the cost of providing a K-12 education in 2009 was $\$ 136,487$ per student, up from $\$ 75,000$ in 1980. Yet, academic indicators suggest that student achievement has stagnated during this same period, or more specifically, the cost has doubled with limited academic benefit from the additional cost.

\section{Academic Benefit of Teachers Obtaining a Graduate Degree}

A strong case can be made that although educators and administrators are obtaining graduate education degrees in greater numbers, the costs per student for a K-12 education have doubled, and there is no evidence of an educational benefit with regard to student achievement within the K-12 system. Several studies have found that on average, teachers with advanced degrees are no more effective than their peers without advanced degrees (Wayne and Young, 2003; Harris \& Sass, 2008; Gordon, Kane, \& Staiger, 2006). The evidence suggests that teachers' obtaining graduate degrees has limited impact on student achievement, but it does inflate the cost. In fact, just recently North Carolina passed a bill that ends the tradition of giving a 10-percent pay raise to teachers who complete a master's degree (Troop, 2013). Of course this is antithetical to the purpose of the step-raise system and long held notions that better prepared teachers will translate to increased student achievement.

As college of education professors who teach methodology and educational psychology courses required as part of most graduate degrees in education, it is our supposition that this antithetical outcome has evolved based on three factors: (1) a desire to increase enrollments (and graduation rates), (2) the need to increase revenue through tuition at our institutions, and (3) a general complacency (even championing) of faculty in education to lower the academic expectations and integrity in many content areas to ensure (1) and (2) are achieved.

In essence, graduate degrees in education are the veritable "low hanging fruit" of academe with an endless supply of students, a need to graduate these same students to demonstrate our utility as an academic institution, while concurrently confirming the ability of our "client" (teachers/administrators in K-12) can obtain their step-raises. To compete successfully against the other teaching and graduate degree programs for this "low hanging fruit" by increasing enrollment figures and tuition revenues and attaining the necessary graduation rates, we don't raise the academic "bar" but are expected to lower this "bar." "Here's the nation's easiest college major" was a report in 2011 by Lynn O'Shaughnessy of Moneywatch on CBS News and discussed how education majors had the lowest SAT scores, but the highest GPA (O'Shaughnessy, 2011). A Faculty Senate Task Force at the University of Arkansas on Grades and Grade Inflation completed in 2006 presented similar findings, with the average college of education GPA .75 standard deviations above that of the rest of the university and ACT scores .75 standard deviations below the university average (Mulvenon, 2006).

\section{Increasing Enrollment}

A natural question is can you increase enrollment (to make money) and graduation rates (to satisfy taxpayers) while maintaining your academic standards (so you can sleep at night)? In other words, as you admit a higher percentage of your applicants, your average admissions test score of your new enrollees decreases, and that is strongly related to lower graduation rates (Hurt, 2012; Leonard \& Pillis, 2008). For example, Arizona State University (ASU) admits 90\% of its applicants and has a six-year graduation rate of 57\% (CollegeMeasures.org, 2012) whereas many similar institutions have graduation rates around of $90 \%$, including UCLA and the University of Michigan. The fact that ASU has a lower six-year graduation rate may be linked to admissions policies associated with providing "opportunities" to all applicants, and perhaps a plan of remediating students lacking academic preparation necessary to be successful. Regardless of the intentions, the graduate rate is deplorable. 
How does a university open the floodgates to admission like ASU did? One approach is to decide that admissions tests are no longer needed. The University of Arkansas College of Education and Health Professions presently does not require the Graduate Record Exam (GRE) for admission to graduate programs in lieu of deferring to academic programs for that decision. As a result, most programs don't require a GRE score for graduate students. The Educational Leadership program (i.e., K-12 school administrators) at the University of Arkansas had a reported cumulative grade point average of 3.92 for graduate students or 92 " $A$ 's" and 8 "B's" for every 100 grades assigned in a 2006 U of A Grade Inflation Study (Mulvenon, 2006). Further, this program's leaders are adamant that requiring the GRE will hurt their program despite it is clear they only assign grades of "A."

Howard Wainer (2011) discusses a number of admissions policies designed to open the floodgates in his recent book, Uneducated Guesses: Using Evidence to Uncover Misguided Education Policies. These include making the SAT optional, substituting achievement for aptitude tests, and giving examinees choice in admissions testing. Wainer explains how each of these policies is ill advised. The bottom line is that in most cases, increasing enrollment means relaxing admission standards and enrolling students who would otherwise not be admitted. The reason they would not be admitted is because they are at risk of not graduating. But, if in addition to lowering admission standards, you also lower your standards in terms of what it takes to pass courses and graduate, then you can achieve the same or even higher graduation rate!

So, let's assume that colleges and universities learn from ASU's mistake and decide to simply lower their academic standards along with lowered admissions standards. When unqualified students are admitted you have the challenge of creating the illusion of academic success. You certainly cannot fail these newly admitted, ill-prepared students! Word would soon get out to other potential recruits that their chances of graduating and the economics of not being competitive with other degree programs may become problematic.

Typically in colleges of education, courses in research methods and statistics are difficult for ill-prepared students. If a graduate student is unable to do basic Algebra, a requirement for graduation from high school, how can this student successfully complete a beginning masters or doctoral level course in research methodology or statistics? To address this issue, colleges of education need to soften academic expectations traditionally employed to train graduate students in methodology and statistics, something that is essential for them to review and conduct research or complete a thesis or dissertation (unless, of course, they choose to do a qualitative study that requires no numbers, but that is another story). Let us reiterate, we are talking about basic Algebra! A new requirement under the soon to be implemented National Common Core Mathematics is that middle school students will be proficient in Algebra. This is rather ironic considering that teachers and administrators seeking graduate degrees are not expected to possess this same level of Algebra proficiency.

To create the illusion of success and academic attainment in graduate programs in any course requiring mathematics or other critical intellectual acumen, you must either eliminate those courses as required or "soften" the academic expectations. The following model is often pursued: (1) simply state a global claim "these courses no longer meet the need of your students," (2) in lieu of in-class exams use take-home tests and portfolios, and (3) employ "authentic assessment" grading scales evaluating each student individually (e.g., different performance expectations). Additional efforts include creating modules of material identified as difficult and "nest" in other courses. For example, add a module on statistics in an unrelated graduate course and then don't test on the material. At the University of Arkansas there is a course on the "Representation of American Education in Popular Film" (CIED 5843). Among the course competencies students will obtain is, "Discuss appropriate use of standardized tests ..." which begs the question, "How?" If you read all 13 course competencies for this course it is clear this is incongruent with any of the other competencies, but it is a module "nested" in another course so students can now claim they had instruction on standardized tests. The more conventional approach would be a graduate course on measurement and assessment where they would actually learn this content, but you will need to be proficient in Algebra. Perhaps we can teach that course to $9^{\text {th }}$ grade students who will be required to actually learn it and they can help their teachers? Finally, for qualifying exams for masters or doctoral degrees, you use take-home tests with open-ended questions. You should never ask graduate students questions they may answer incorrectly as this is incongruent with our "happy clappy" where academics equal philosophies in colleges of education. Again, word would soon get out to the potential recruits that there is a possibility of academic rigor existing in their program of study.

We suspect there would be limited concern by the general public if we report we are graduating education students with advanced degrees who are ill equipped to perform competently in the K-12 system. After all, there is existing evidence that education majors represent the bottom of the barrel in terms of qualifications. In a recent study by Wai, Lubinski, and Benbow (2009), test scores were examined for about 400,000 participants in a longitudinal study. The only group 
that scored below the mean on all three composite measures (verbal, mathematical, and spatial ability) was comprised of participants who received Bachelors, Masters, and Doctorates in education, and for those whose occupation was classified as education. Further, those in the survey with an Ed.D. degree also scored well below the mean on all three measures (see their Figure 5). For the GRE test data, education was the only group that scored below the mean on both the math and verbal tests, when compared with arts, biological science, business, engineering, humanities, math, physical science, and social science. More specifically, education scores were not only lower but they were so low they skewed the distribution so as a group they were the only content area below the overall mean. Thus, perhaps the collateral damage that would come with continuing to open the admissions "floodgates" and lowering our academic standards in education even further is not worth worrying about, as at this point we are already the SS Educational Titanic streaming to the bottom. Why would re-arranging the deck chairs be a problem?

Is this a college of education issue or is it occurring in other fields? What if we graduate physicians who struggle to accurately diagnose and treat illnesses? What if we graduate engineers who are " $D$ " students when it comes to designing bridges and buildings? Let's change the medical and bar licensing exams from multiple choice to take-home essay questions. Does it matter as long as they paid their tuition and fees? Who will be held accountable for the unspeakable consequences of these decisions? Alas, what about the poor souls in the K-12 system when we hire teachers and administrators who are even less prepared than ever before? University administrators may like to focus on the number of advanced degrees in education they are producing to "help" the K-12 systems, but in reality they are the bankers giving bad loans with unsecured credit, while passing the cost of their educational malfeasance on to the $\mathrm{K}-12$ system and the unfortunate student consumer! Everyone is left holding the bag for the costs associated with this academic malfeasance - which sounds very similar to the banking crisis. The K-12 system and higher education enjoy claiming all teachers meet the Highly Qualified Teachers (HQT) standards as demonstrated by $100 \%$ passing rates on the Praxis II exam. However, if you review the "cut-scores" required to "pass" the Praxis II exams, most states simply select a passing score in the bottom-quartile of the distribution of possible scores (Morton, 2012). In some cases, the required cut-score to pass the Praxis II exam is only percentage points above random guessing. HQT is a different beast, but consistent with the message we are presenting, which is that the labels and outcomes do not represent sound academic models or expectations.

\section{Discussion}

The process of lowering academic standards as stated is often subtle, usually involves claims of academic excellence, concomitant with claims of "serving" students and educational stakeholders. In our experience it consistently involves four elements: (1) disregard and/or elimination of traditional entry requirements to doctoral intensive research institutions, (2) direct requests to eliminate components of courses that present challenges to ill-prepared students, (3) creation of redundant courses that list the components as part of the course objectives but don't actually teach the material or require that it be learned, and (4) elimination of methodology requirements for graduate degrees. Each of these four elements has been used to increase enrollment for on-line programs, courses, and degree completion. More recently, the same process is also being employed with more traditional on-campus programs and degrees.

To demonstrate, Student A is admitted to a doctoral program with a Graduate Record Examination (GRE) score that ranks at the 16th percentile on the quantitative section (141 on new scale, 330 on old scale). It is reasonable to infer this student is weak in mathematics. To address this issue, programs admitting these ill-prepared students may approach methodology or educational psychology faculty to discuss course requirements and academic expectations in required core courses for either on-campus or on-line courses. The normal claim is "this course is not what our students need" (based, of course, on the premise they are aware their students are not prepared) or "they don't need to know how to do statistics, they just need to be able to interpret the results" and it usually closes with "if you can't make these changes we will develop our own course to meet the needs of our students". The use of key phrases such as "meet the needs of our students" is essential in this process, as it doesn't convey eliminating standards or lowering academic expectations, but is a great omnibus catchphrase to create the illusion that the course is now somehow inappropriate. Finally, you champion the modifications as "meeting student needs" and serving educational stakeholders by increasing the number of degrees attained on the Mississippi Delta, west Texas or other regions. A strong case can be made that the goal of these programs is not to teach and develop outstanding doctoral students; rather, it is to simply graduate students, which may be a very different academic outcome.

A colleague of ours once asked us why we care. Basically, his view was educators and administrators have long been "fast-tracked" to degrees that may be academically suspect in nature so why does that bother us? After all, enrollments are growing at our institutions, modest raises have been provided, and we even get some new whiteboard markers for our classrooms. What are the real costs? Academic integrity may be fleeting, but it hasn't completely succumbed to the desire of those seeking to grow enrollments, raise tuition, and adopt a social justice model for granting of degrees. 
Doctoral intensive research institutions should not, and cannot compete, with the plethora of "McDistance" online education programs and for-profit education diploma mills, but we can provide and champion academically outstanding degree programs that challenge and raise the bar in terms of what to expect from our graduates. It is staggering to the mind to believe that expecting a little homework, a few exams, a research paper, and a comprehensive final exam in all courses is inappropriate at the graduate level. But, hey we aren't really talking about education. The discussion is about money, degrees, and the politics associated with both.

\section{References}

Bankston, C. (2011). The mass production of credentials: Subsidies and the rise of the higher education industry. The Independent Review, 15.3 (Winter 2011): 325-349.

Congressional Documents and Publications. (2012, Jul 18). House education and the workforce subcommittee on higher education and workforce training hearing.

CollegeMeasures.org (2012). Graduation Rates for Arizona State University accessed on October 23, 2012 online at http://collegemeasures.org/4-year_colleges/institution/arizona-state-university-az/scorecard/graduation-rates/.

Gordon, Kane, \& Staiger. (2006). Identifying effective teachers using performance on the job. Hamilton Project Discussion Paper (March 2006), The Brookings Institution.

Harris \& Sass, (2007). Teacher training, teacher quality, and student achievement. Working paper 3 (March 2007). National Center for Analysis of Longitudinal Data in Education Research, Calder Urban Institute

Hurt, E. (2012, Spring). The marketization of higher education. College Literature, 39.2, 121-132. http://dx.doi.org/10.1353/lit.2012.0013

Leonard, B. \& Pillis, E. (2008). Aligning admissions standards with graduation and retention goals: A case study from the University of Hawaii. The International Journal of Learning, 15 (6).

Max \& Tierney. (2011, Oct 30). Now more than ever, a need for bold ambition. The Chronicle of Higher Education.

Morton, K. (2012). Arkansas teacher licensure cut scores: Do they indicate highly qualified teachers? A dissertation completed in fulfillment of a doctorate of philosophy at the University of Arkansas, May 2012.

Mulvenon, S. (2006). Faculty Senate Task Force on Grades and Grade Inflation. A report presents to the Faculty Senate at the University of Arkansas on April 23, 2006 and available upon request via seanm@uark.edu.

Ohio Education Association. (2013). "OEA Teacher Salaries: Step Increases" accessed November 15, 2013, http://www.ohea.org/step-increases.

O'Shaughnessy, L. (2011). Here's the nation's easiest college major. Accessed on-line on October 11, 2012 at $\mathrm{http} / / / \mathrm{www} . c b s n e w s . c o m / n e w s /$ heres-the-nations-easiest-college-major/

Troop, D. (2013). End to pay bump for teaching master's degree squeezes some education colleges. The Chronicle of Higher Education, November 18, 2013.

Wellman, J. (2008, Nov/Dec). The higher education funding disconnect: Spending more, getting less. Change 40.6, 18-25. http://dx.doi.org/10.3200/CHNG.40.6.18-25

Texas Higher Education Coordinating Board, "Closing the Gaps: 2010," accessed May 23, 2011, http://www.thecb.state.tx.us/index. cfm?objectid=858D2E7C-F5C8-97E9-0CDEB3037C1C2CA3.

For 2009 ASU enrollment statistics; for 2010 enrollment at ASU online, see http://asunews.asu.edu/20100909_enrollment.

The University of Texas at Austin Office of Information Management and Analysis, General Analysis-Faculty/Staff, 3, accessed May 22, 2011, http://www.utexas.edu/academic/ima/sites/default/files/SHB10- 11Faculty-Staff.pdf.

Digest of Education Statistics (2010). Institute of Education Sciences, National Center for Education Statistics. http://nces.ed.gov/programs/digest/d10/tables/dt10_071.asp

U.S. Census Bureau. (2011). Census Bureau reports public school systems spend $\$ 10,499$ per pupil in 2009. U.S. Census Bureau, May 2011, http://www.census.gov/newsroom/releases/archives/facts_for_features_special_editions/cb11-ff15.html

College of Liberal Arts analysis of data drawn from Integrated Postsecondary Education Data System, 2009, http://nces.ed.gov/ipeds/ datacenter/Default.aspx.

Wayne, A. \& Youngs, P. (2003). Teacher characteristics and student achievement gains: A review. Review of Educational Research, 73, 89-122. http://dx.doi.org/10.3102/00346543073001089 